\title{
AN ANALYSIS OF BUYER-SUPPLIER COLLABORATION IN THE SOUTH AFRICAN TEXTILE INDUSTRY
}

\author{
H Parker, Graduate School of Business, University of Cape Town
}

\begin{abstract}
Purpose: The purpose of this article is to explore perceptions regarding buyer and supplier collaboration around product development. The aim is to gain an understanding of which factors influence buyer-supplier collaboration outcomes in the South African textile industry.
\end{abstract}

Methodology: This study comprised two data collection stages. The first stage comprised the design and administration of a questionnaire survey. The second stage utilised a qualitative interview methodology and entailed interviewing a subset of the questionnaire respondents in order to probe respondents' own experiences in collaborative product developments and their perception of the factors that determine collaboration outcome.

Findings: This study has shed light on the experiences of South African firms in the textile industry engaging in buyersupplier collaboration around product development. While this study is exploratory, it has provided evidence that there are certain factors which are perceived to have a significant influence on collaboration.

Implications: Under the past protective shield of tariffs, South African clothing and textile manufacturers could afford to allow an adversarial mode of operation to perpetuate inefficiencies. However, the increasing external pressures, including the very real threat of overseas competition, heighten the need for collaboration between buyers and suppliers. This relates, in particular, to collaboration aimed at new product development, which can be seen as a new imperative for the survival and growth of this industry. Currently, there are numerous barriers to effective collaboration. The overwhelming power of retailers in the value chain is one such barrier, as it creates an environment which is pressurised, strained and not conducive to buyer-supplier collaboration.

Contribution and Value: Studies on collaborative new product development have primarily been done in developed countries, with a focus on technology intensive industries. This study sheds light on the dynamics of collaborative new product development in the South African context. It is a mature industry which is facing severe challenges. Factors which influence the performance of collaborative projects in this context were explored and hold important implications for managerial action, and government support for buyer-supplier collaboration initiatives.

Keywords and phrases: Buyer-supplier linkages, new product development, collaboration, alliances, new product development, textiles, clothing.

\section{INTRODUCTION}

This paper explores buyer-supplier collaboration in the South African clothing and textile industry sector. This is one of South Africa's largest manufacturing sectors that, particularly in the Western Cape, is an important provider of employment and a significant contributor to GDP. The industry which once had a favourable position in the economy, has undergone a dramatic decline, with the textile industry sector experiencing severe job losses leaving many firms facing closure (Kriel, 2006).

South African firms have found it increasingly difficult to compete with low cost, foreign (notably Chinese) imports of commodity textiles, and this has intensified the need for textile firms to innovate and develop higher profit margin, specialty textiles.

This paper highlights the perceptions and experiences of buyers and suppliers attempting to collaborate in order to develop new products. This provides an insight that is crucial for directing and focusing industry support to ensure that it is most beneficial for firms in the textile industry.

Collaboration between buyers and suppliers has been promoted and encouraged by a number of governmental organisations (Barnes \& Morris, 2000). There is however a need for more specific recommendations on how firms can build sustainable collaborative relationships within industries that are suffering (Barnes \& Morris, 2000). This exploratory study addresses this need by identifying the 
issues and challenges that textile firms face in trying to collaborate, and what factors influence collaboration outcomes.

This paper firstly provides a background to the South African textile industry and to buyer-supplier collaboration. Secondly, the objectives of the paper are discussed. Thirdly, the methodology employed for this study is outlined. Fourthly, the findings of this study are discussed and, finally, conclusions are drawn and recommendations are made for further research.

\section{BACKGROUND}

The clothing and textile industry is a significant employer in South Africa's manufacturing sector. The industry has however suffered a severe decline in performance over the recent years. This has been due to the phasing down of the customs tariffs and due to the increased volume of imports. Local manufacturers are finding it impossible to compete on the basis of price. This has forced many manufacturers to start producing specialty (as opposed to commodity) type products and to move into niche markets.

There is thus an increased imperative for South African textile firms to become effective at new product development. New product development is however regarded as risky, and very costly (Riek, 2001). Hence, examining ways and means of reducing this risk and increasing the probability of successful new product development is valuable. One such way, highlighted by the literature, is buyer-supplier collaboration (Petersen, Handfield \& Ragatz, 2003:284).

In order to understand the decline in the performance of the South African clothing and textile industry, it is necessary to examine the effect that a history of tariff protection had on the industry. In describing the development of the textile industry from the 1920's to the 1970's, Barker quotes "behind protective tariff and quota walls" (Maree, 1995:24).

Once an implied pledge of protection had been given and received, there was understandably little disposition on the part of textile manufacturers to consider anything that might tend to limit or regulate the operation of their mills, even temporarily or only tacitly. So the hint of their concentrating on specialised output, with no certainty on how that might accord with future trends, was repugnant, even though at the time it might have helped in attaining growth and stability. In any event, when an industry has been conceived, born and brought up in the expectation that its well-being will be ensured by tariffs, it is likely to have a built-in mistrust of its own ability to compete on any other basis. (Barker, 1963:291-2)

Thus, the phasing down of customs tariffs and the increased volume of imports have exposed weaknesses in an industry accustomed to heavy protection.

\section{The Textile-Clothing Pipeline}

A schema of the textile-clothing pipeline is shown in Figure 1.

Figure 1: Textile-Clothing Pipeline

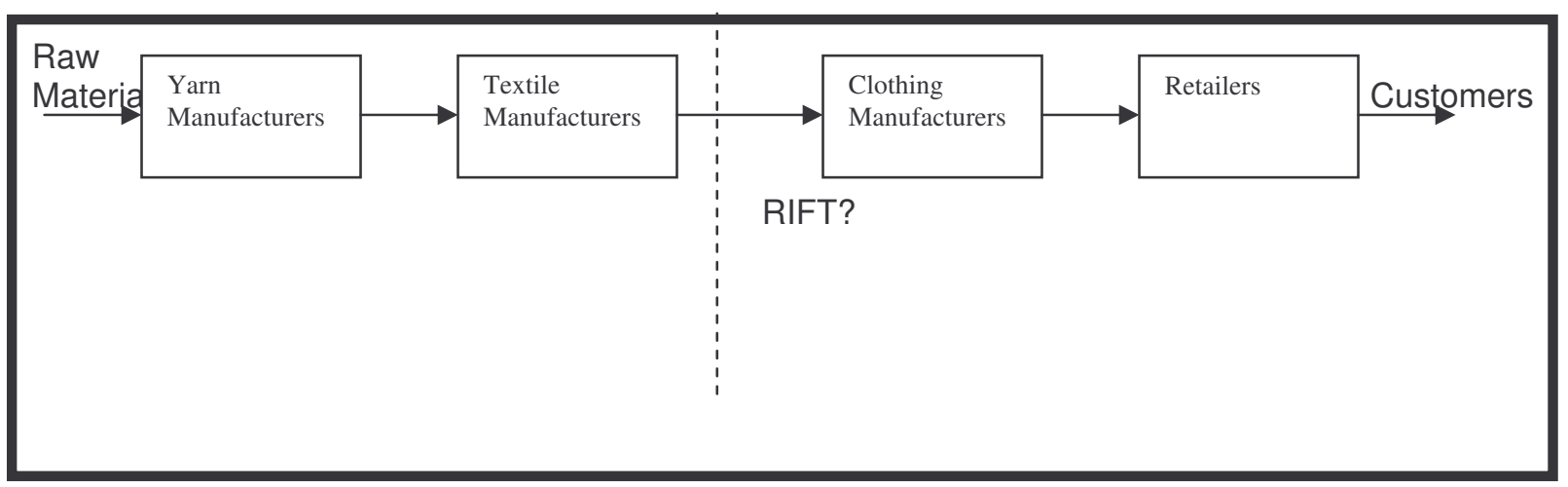


The above four stages are the major steps in converting raw material to a purchasable garment. There may be numerous additional steps between those shown (for example, dyeing or printing) but they have been omitted for simplicity of analysis. It has also been found that, often, many large retail groups are so closely associated with specific clothing manufacturers, that a separation between retailer and clothing manufacturer is difficult.

Coleman (1990), who did a gap analysis of the differences between textile buyers' expectations and textile suppliers' perceptions regarding the quality of textiles, found that communication between the textile and clothing manufacturers and retailers was unacceptably low, and that co-operation between the textile and clothing sector in South Africa was poor.

A finding by Hopper (1990), further explained the antagonism between the textile and clothing sectors. It showed that volatility in demand is increasingly amplified as one moves from customer to retailer to clothing manufacturer to fabric manufacturer and to yarn manufacturer. For example, a $10 \%$ fluctuation in consumer spending on clothing, leads to a $40 \%$ fluctuation in demand for yarn products. Hopper (1990:13) further states, "the variability encourages in-fighting in the industry with the different stages attempting to pass on the negative effects to other sectors in the pipeline. This does nothing to improve the competitive position of the industry and merely shifts the burden from the stronger to the weaker participants. The overall effect of this variability is to raise costs in the industry and thus adversely affect the long-term competitive position of the industry."

A major barrier to creating buyer-supplier collaborative relationships in the textile value chain is the dominant and threatening role that retailers play. This has been observed by Morris (2005:1) who notes that: "The clothing and textile value chain is dominated by large retailers, branded manufacturers and marketers who control global production networks and stipulate supply specifications. These retailers are able to wield significant power over manufacturers in terms of price, quality, lead times and raw material inputs."

Collaboration has been referred to as a partnering relationship between firms by Child, Faulkner, and Tallman (2005). A review of the literature has revealed a variety of perspectives regarding collaboration in the new product development process. These perspectives fall into three broad categories, namely: benefits of collaboration; risks of collaboration; and factors that increase the success of collaborative efforts (Littler, Leverick \& Bruce, 1995).

The benefits of buyer-supplier new product development collaboration, which have been cited in the literature, include a reduction in product development cost and time and a reduction in uncertainty associated with innovation (Petersen, Handfield \& Ragatz, 2003). Researchers have noted that collaboration can expose collaborating companies to the risk of losing valuable technical advantages to competitors through intentionally or unintentionally revealing commercial secrets (Hamel, 1991). Other risks which have been documented are that collaboration often requires additional efforts from both buyer and supplier firms and may thus result in increased costs and time delays. Factors that positively influence buyer-supplier collaboration success, which have been cited in the literature, include frequent communication between firms and trust between firms. A factor which has been found to be beneficial in certain instances but has a negative influence in other instances, is a formal set of rules of engagement. An extensive review of the literature pertaining to factors influencing the success of collaboration aimed at new product development, shows that there are a number of factors which seem to have a different influence on success in different contexts. It was thus felt that as most of the studies in this area had been done in the USA and Europe, it would be necessary to do a study in the South African context particularly in a industry that is exposed to great challenges, such as the clothing and textile industry in order to better understand collaborative new product development, and the relevance of factors identified in the literature to the South African context.

Buyer-supplier collaboration in the clothing and textile industry is not a new phenomenon. Richardson (1972), in his seminal work, observed how Marks and Spencer (M\&S) had extensive relationships with their suppliers, and how M\&S engaged in collaborative new product development with their suppliers. These collaborative relationships between M\&S and their suppliers were beneficial to M\&S. Recent reports, however, indicate that suppliers may have suffered certain losses in these relationships. 
Relatively recently, leading UK newspapers (for example, The Daily Telegraph, June 30, 2000, article by Rankine) reported on a case where Baird's, a large knitwear manufacturer who had been a significant supplier to M\&S, suffered huge losses and needed to close some of its manufacturing facilities as M\&S refused to continue a supplier relationship. Baird's lost heavily as there was no legal contract in place. While an implied pledge existed between the two firms, the court ruled that there were no legal contractual obligations forcing M\&S to maintain their supplier relationship. They were therefore able to break ties.

This particular case highlights the vulnerability of suppliers in buyer-supplier collaboration arrangements in the clothing and textile industry. It further emphasises the importance of understanding the factors that facilitate collaboration, or how collaboration should be managed, so that collaboration can really be mutually beneficial to both firms.

\section{OBJECTIVE}

In view of the lack of research done on buyer-supplier collaboration in developing country contexts, this study aims to shed light on the experiences of South African firms in the textile industry. Key objectives of this study were to explore the following:

- What are the main reasons South African clothing and textile firms engage in collaboration in the new product development process?

- What has the effect of collaboration on the new product development process been?

- Which factors have been found to influence the outcomes of collaboration?

\section{METHODOLOGY}

This study comprised two data collection stages. The first stage comprised the design and administration of a questionnaire survey. The second stage utilised a qualitative interview methodology and entailed interviewing a subset of the questionnaire respondents in order to probe respondents own experiences in collaborative product development and their perception of the factors that influence collaboration outcome.

\section{Stage One}

Stage one entailed the design and administration of a questionnaire survey. The survey required respondents to indicate what their reasons for collaborating in new product development were, and what effect collaboration had on the process. The survey items were drawn from Littler, Leverick and Bruce (1995:22-23).

Two hundred companies were randomly selected from the South African Textile Federation and Clothing Federation directories. Each selected company was contacted to ascertain the name of the person who had the greatest responsibility for new product development in the company. A questionnaire was then sent directly to the identified person. Of the 200 companies that the questionnaire was sent to, 32 responded fully.

The findings regarding the questionnaire survey are described in the Findings section, in the subsections headed "reasons for collaboration", and "the effect of collaboration on the product development process".

\section{Stage Two}

In the second stage, these 32 respondents were categorised according to their experience of collaborative new product development. The categorisation method used by Littler, Leverick and Bruce (1995:25) was followed in this study. Respondents who had collaborated on less than $25 \%$ of their new product developments were categorised as LESS experienced while those respondents who had collaborated on $25 \%$ or more of their new product developments were categorised as MORE experienced in collaborative product development. 20 of the 32 questionnaire respondents could be classified as MORE experienced in collaborative new product development. These 20 firms (categorised as MORE experienced) comprised the focal sample for this stage of the study. 
Interviews were conducted with these 20 firms and managers at the firms were asked to draw from their collaborative product development experience and describe the factors they had found that influenced the collaboration outcomes. The 20 firms represented all four types of firms comprising the textile value chain, namely yarn manufacturers, fabric manufacturers, clothing manufacturers and retailers. The interview process and data analysis employed a qualitative methodology described by Leedy and Ormrod (2001).

The methodology used to explore collaborative new product development was as follows:

1) Interviews were conducted with firms identified as having experience with buyer-supplier collaborative new product development. The manager interviewed at each firm, was selected by virtue of his or her knowledge of the firm's collaborative new product development activities.

2) Each manager was asked about:

- Their buyer-supplier collaboration experiences

- Their perceptions regarding buyer-supplier collaboration

- Factors which, according to their experience, influence collaboration outcomes

3) Detailed notes were taken during each interview. The interview data was analysed using a technique called "content analysis". Leedy and Ormrod (2001:155) describe content analysis as follows: "content analysis is a detailed and systematic examination of the contents of a particular body of material for the purposes of identifying patterns, themes, or biases."

4) The themes that emerged from the content analysis procedure were examined by observing the frequency with which the factors associated with these themes were mentioned by managers at the different firms. The contexts within which these themes were mentioned were also examined.

In order to check manager competency for this study, we asked managers two questions:

What was their job title and primary responsibilities and what percentage of the firm's collaborative developments have they personally been involved in? All the managers participating in this research had been involved in eighty to one hundred percent $(80-100 \%)$ of the firm's collaborative developments. This indicated that they were competent to answer questions regarding the firm's collaboration activities. Their job title indicated that they held senior management positions in their firms and that they actively participated in the firm's new product development activities and in discussions with the firm's suppliers and customers.

The findings from this second stage are described in the Findings section, in the sub-section headed "factors influencing the outcome of collaborative product development."

\section{FINDINGS}

The findings related to the three key objectives of this study are discussed in the following three sections, entitled: reasons for collaboration in new product development; the effect of collaboration on the new product development process; and factors influencing the outcome of collaborative product development.

\section{Reasons for Collaboration in New Product Development}

The results of an analysis of the questionnaire responses regarding reasons for collaboration are presented in Table 1. Respondents were asked to rate each reason on a five point scale where (1) represented "very important" and (5) "unimportant". The table is arranged in order of importance of perceived reasons. The reported mean score was found by calculating the average rating of all the responses to a particular question. 
Table 1: Importance of reasons for collaborating in product development

\begin{tabular}{|l|l|}
\hline Reason for Collaboration & Mean Score \\
\hline To increase the speed of the development process. & 1.30 \\
\hline In response to key customer needs. & 1.48 \\
\hline $\begin{array}{l}\text { To take advantage of a market opportunity and the required } \\
\text { expertise is not possessed within the company. }\end{array}$ & 1.68 \\
\hline To reduce research and development risks. & 1.94 \\
\hline To reduce research and development costs. & 1.94 \\
\hline In order to be more innovative in product development. & 1.98 \\
\hline In response to technology changes. & 2.00 \\
\hline To broaden product range. & 2.23 \\
\hline In order to be more objective in product development. & 2.29 \\
\hline In response to a management initiative. & 2.50 \\
\hline Due to a collaborative corporate culture. & 2.61 \\
\hline In response to key supplier needs. & 2.74 \\
\hline In order to conform to standards. & 2.77 \\
\hline In order to achieve continuity with prior products. & 2.83 \\
\hline
\end{tabular}

Respondents rated the need to increase the speed of the development process as the prime reason for collaboration. Other main reasons were given as: responding to key customer needs; taking advantage of a market opportunity, when the required expertise and skills are not possessed within the company to enable it to capitalise on the opportunity; and reducing research and development risks and costs.

\section{The Effect of Collaboration on the New Product Development Process}

The questionnaire facilitated an assessment of each respondent's perception of the effect of collaboration on the development process. Respondents were required to indicate their level of agreement with statements referring to different effects. A five-point scale, where (1) represents "strong agreement" and (5) "strong disagreement" was used. The percentage of respondents showing agreement or disagreement with each statement is shown in Table 2.

Table 2: The effect of collaboration on the new product development process

\begin{tabular}{|l|l|l|}
\hline Collaboration Generally.... & $\begin{array}{l}\text { Agree/ Strongly } \\
\text { Agree } \\
(\%)\end{array}$ & $\begin{array}{l}\text { Disagree/ } \\
\text { Strongly } \\
\text { Disagree (\%) }\end{array}$ \\
\hline Accelerates product development. & 85 & 6 \\
\hline $\begin{array}{l}\text { Makes product development more responsive to customer } \\
\text { needs. }\end{array}$ & 69 & 3 \\
\hline Allows companies to responds better to market opportunities. & 69 & 3 \\
\hline Makes product development more efficient. & 66 & 9 \\
\hline $\begin{array}{l}\text { Leads to frustration if the other party becomes less } \\
\text { committed.. }\end{array}$ & 56 & 16 \\
\hline $\begin{array}{l}\text { Increases the risk that products become too specified to a } \\
\text { single customer's needs. }\end{array}$ & 31 & 16 \\
\hline $\begin{array}{l}\text { Increases the risk that the collaborative relationship } \\
\text { continues after the commercial benefit has gone. }\end{array}$ & 31 & 28 \\
\hline Increases the risk that collaborators become competitors. & 28 & 38 \\
\hline Increases the probability of leakage of company information. & 28 & 28 \\
\hline Leads to conflict due to differing aims of participants. & 23 & 40 \\
\hline Complicates product development. & 19 & 53 \\
\hline Makes the development more difficult to control. & 6 & 66 \\
\hline Causes the development to take longer. & 3 & 63 \\
\hline Makes the development more costly. & 3 & 84 \\
\hline
\end{tabular}


The table shows that the overwhelming majority of the respondents felt that buyer-supplier collaboration had a positive impact on their new product development efforts. Benefits realised from collaboration included accelerated product development, increasing response to customer needs, the enablement of an organisation to take advantage of market opportunities, and making product development more efficient. Accelerating product development is particularly important in the clothing and textile industry as fashion is fast paced, and the need to develop products quickly to meet this ever changing market is an imperative.

The disadvantages of collaboration which were acknowledged were that products developed collaboratively tend to become too specified to a single customer's needs. While views were varied, a larger percentage of respondents tended to disagree with the statements referring to negative effects of collaboration.

In this study of textile and clothing manufacturers, there appears to be a mixed response about whether information leakage is a real risk. Responding to the statement, collaboration generally increases the probability of leakage of company information, $28 \%$ agreed and $28 \%$ disagreed. While a clothing manufacturer that was interviewed expressed a strong view that the leakage of proprietary information to a collaborative partner constituted a real fear for his company, a consultant to the textile industry expressed a very different opinion. The consultant had the following perspective: "The overwhelming fear of losing information is not warranted in the South African textile industry, and is debilitating. It is not justified as a reason for not collaborating in product development."

\section{Factors Influencing the Outcome of Collaborative Product}

This section describes the findings from stage two of this study. In stage two of the study, interviews were conducted with firms identified as having experience with buyer-supplier collaborative new product development. A process of content analysis was used to examine the interviews in order to identify factors found to influence collaboration outcomes.

During the process of coding the data (interview transcripts) and looking for patterns (Leedy \& Ormrod, 2001:155), a number of themes emerged. The table that follows below shows how many firms mentioned a particular factor as being influential to the collaboration process and, ultimately, to collaboration outcomes.

Table 3: Respondent specified factors influencing the outcome of collaborative product development

\begin{tabular}{|l|l|}
\hline Factor & $\begin{array}{l}\% \text { of Respondents } \\
\text { Mentioning Factor }\end{array}$ \\
\hline Transparency/Trust/Honesty & 75 \\
\hline Commitment toward the development & 55 \\
\hline Full and early information disclosure & 50 \\
\hline Frequent communication between participants & 50 \\
\hline Equity in distribution of benefits & 35 \\
\hline Compatibility of company cultures & 25 \\
\hline Confidence in the suppliers capabilities & 25 \\
\hline Clearly defined objectives and project milestones & 25 \\
\hline Understanding of roles and responsibilities & 15 \\
\hline Agreement regarding order quantities of new product & 15 \\
\hline $\begin{array}{l}\text { Objectivity and perseverance in resolving development } \\
\text { problems }\end{array}$ & 10 \\
\hline
\end{tabular}

Trust, commitment and communication between collaborating firms emerged as the most important factors that determine successful collaboration outcomes. An analysis of the interview transcripts shows that a "lack of trust and transparency" plagues the textile industry in South Africa and is a real source of tension between buyers and suppliers. 


\section{A Manager's Experience: Dealing with a Lack of Transparency}

Retailer $Z$ and Textile Manufacturer $Y$ had collaborated for 16 months on the development of Product $X$. When Manufacturer $Y$ successfully developed Product $X$, Retailer $Z$ refused to purchase it. Unbeknown to Manufacturer $Y$, Retailer $Z$ had been working with another textile manufacturer to develop the same product. Retailer $Z$ delayed ordering product from Manufacturer $Y$ for 10 months, until the other textile manufacturer had developed the same product. Retailer $Z$ had the hidden motive of not wanting to purchase from only one supplier, and therefore be in a vulnerable position in the buyer-supplier relationship. Having one supplier leaves a buyer vulnerable to being locked into a relationship with the supplier.

Despite this negative experience, Textile Manufacturer $Y$ believes collaboration is good. "We believe in collaboration, but it has to be open and honest. We don't have transparency and it's a stumbling block". Textile Manufacturer Y further explained that while trust is important, a break in trust between the firms is very hard to repair and it is therefore vital that both firms appreciate the need to build and maintain trust. Lane and Bachmann (1998) describe trust as "fragile" and have observed that once trust has been broken, it is extremely difficult to rebuild.

Commitment was also highlighted as a key factor influencing the outcome of collaboration. The finding that trust and commitment are perceived to have a strong effect on buyer-supplier collaboration is supportive of the work of Morgan and Hunt (1994).

The executive director responsible for research and development at a fabric manufacturing plant, who had worked extensively in the U.K. textile industry, felt that local South African clothing manufacturers and retailers are notorious for not disclosing all the necessary information, and for not involving suppliers early enough in the development process. He contrasts this to his U.K. experience: "The U.K. textile industry faced the challenge (to combat external competition) already. The surviving fabric manufacturers all depend heavily on collaborative development for their core items reaching from raw material through to retail. A large percentage of their time is spent in 'pre-seasonal' planning between all parties. Much time is spent at the initial product development phase". The 'selective', rather than full disclosure of necessary information in a collaborative relationship between textile and clothing manufacturers is a source of frustration for textile manufacturers. $50 \%$ of the managers mentioned frequent communication and full and early information disclosure as important to success.

The compatibility of firm cultures between buyer and supplier was mentioned by $25 \%$ of the managers as being important. Closely linked to the concept of firm culture is the concept of firm capabilities. Clothing manufacturers and retailers perceptions of specific suppliers' capabilities, also strongly influence their choice of collaboration partner. The ability of a supplier to bring the necessary expertise and capabilities to the collaboration process has been described as being crucial to its success.

The managers, who highlighted factors associated with buyer-supplier transactions (such as, equity in distribution of benefits and agreements regarding order quantities) were primarily suppliers in the buyer-supplier collaboration. These managers reinforced the "Baird's - Marks and Spencer" experience described in the background section of this paper. Baird's, a knitwear supplier to Marks and Spencer, suffered severe losses because no formal contractual agreement existed between themselves and Marks and Spencer in the UK.

The need for a formalised agreement regarding order quantities of the new product, once it has been developed, is particularly emphasised by textile manufacturers and suppliers in the textile-clothing pipeline. This emphasis draws attention to Hopper's (1990) observation that volatility in demand is increasingly amplified as one moves from retailer upstream to textile manufacturer. The need for formalised agreements is perceived as a way in which textile manufacturers can reduce the amplified risk and volatility they are exposed to. It has however been found by Lawton Smith et al. (1991:460) that formalised agreements tend to undermine trust in the collaboration.

A number of researchers such as Kaplinsky (2005) and Morris and Barnes (2006) have noted how retailers (the final buyers) in the South African clothing and textile value chain display much power and play an overwhelmingly dominant role in the value chain. They dictate terms to suppliers further 
down the value chain. Hence, clothing, fabric and yarn manufacturers are subservient to terms enforced by much stronger buyers, namely clothing retailers. Equity in the distribution of benefits derived from collaboration is consequently problematic.

A number of the managers interviewed expressed the view that the presence of defined objectives and clarity around roles and responsibilities provided the collaborative new product development with a structure which facilitated efficient buyer-supplier collaboration. Clarity around roles and responsibilities of each collaborating firm was also found to reduce ambiguity and uncertainty in the collaboration process.

The need for objectivity and perseverance in resolving problems in the collaborative product development process was highlighted by managers. A particular manager expressed the view that suppliers in the buyer-supplier relationship are most often held responsible for failures. It was felt that new product development was by its nature very risky and new products fail despite considerable effort from both collaborating partners. A respondent, in drawing from his experience in collaborative product developments with European and American firms, reported a high level of objectivity from overseas firms in attempting to deal with problems and their willingness to persevere and work with South African supplier firms to resolve problems. This he believes contrasts with South African firms where finding a scapegoat is a priority, rather than objectively resolving the problem.

\section{CONCLUSIONS}

In this study of buyer-supplier collaboration aimed at new product development, the main reasons for collaboration indicated were to: accelerate the product development process; to respond to key customer needs; to take advantage of a market opportunity when the required expertise and skills are not possessed within the firm; and to enable the firm to capitalise on the opportunity and to reduce research and development risks and costs.

There is strong evidence from the respondents' perspectives that benefits are realised through buyersupplier collaboration. The greatest benefits are perceived to be: an increase in the speed of the development followed by increasing response to key customer needs and the enablement of an organisation to take advantage of market opportunities for which sufficient skills or expertise is not possessed for the opportunity to be exploited independently. Respondents do perceive to be yielding the advantages for product development that they expect. This is evidenced by the link between the reasons for collaboration (Table 1) and the effect of collaboration on the new product development process (Table 2).

The exploration of the experiences of firms with buyer-supplier collaboration yielded a number of insights. From this exploration, factors were identified which firms had found to have a significant influence on collaboration outcome. Factors described as critical were those primarily referring to the relationship between the collaborating partners, that is, the need for trust, commitment and communication between firms, the compatibility of company cultures, and confidence in a collaboration partner's capabilities. Additional factors drawn from managers' experiences with collaboration included: the perception of equity in the distribution of benefits, the need for agreements regarding order quantities of the new product, clearly defined objectives and responsibilities, and objectivity and perseverance in resolving development problems.

The examination of experiences revealed a number of concerns held by firms engaging in collaboration. These concerns expose a number of tensions between buyers and suppliers in the South African clothing and textile industry. Tensions seem to be ingrained in the industry and act as a barrier to effective and sustainable collaboration. Under the past protective shield of tariffs, the South African textile and clothing manufacturers could afford to allow tensions between buyers and suppliers to perpetuate inefficiencies. However, the increasing external pressure (including the very real threat of overseas competition) heightens the need for collaboration and co-operation between industry players.

A key contribution of this study is that it shows that, in the challenging and pressured environment of the South African clothing and textile industry, it is essential for firms to understand the importance of 
factors associated with the buyer-supplier relationship, and to go beyond merely investing time in developing the factors associated with the buyer-supplier transaction when attempting to collaborate.

Studies on collaborative new product development have primarily been done in developed country contexts with a focus on technology intensive industries. A key contribution of this study is that it sheds light on the dynamics of collaborative new product development in the South African context in a mature industry which is facing severe challenges. A direct implication of this study is that it is imperative that managers at clothing and textile firms and government support agencies, which promote buyer-supplier collaboration, understand the complexities of collaboration in South Africa and the importance of various factors in ensuring successful collaboration.

\section{SUGGESTIONS FOR FURTHER RESEARCH}

- Further insight into the complexities of collaborative new product development in the South African textile and clothing industry could be gained by conducting this study on a larger scale.

- A replication of this study in another developing country would be useful in assessing whether the results of this study are specific to the South African textile industry.

- A longitudinal study would yield important insights into how buyer-supplier collaboration processes evolve over time, and whether certain factors change in importance as collaboration processes evolve.

\section{REFERENCES}

Barnes J \& Morris M. 2000. Improving operational competitiveness through firm-level clustering: a case study of the Kwazulu-Natal benchmarking club. CSDS Working Paper Number 24.

Barker HAF. 1963. A comment on textile development in South Africa. South African Journal of Economics, 31:285-303.

Child J, Faulkner D \& Tallman S. 2005. Cooperative Strategy. London: Oxford University Press.

Coleman P. 1990. A Gap Analysis of Quality: a Study of the Discrepancies between the Suppliers and Purchasers of Textiles in South Africa. Technical Report, Graduate School of Business, University of Cape Town.

Hamel G. 1991. Competition for competence and interpartner learning within international strategic alliances. Strategic Management Journal, 12:83-104.

Hopper G. 1990. Industry Pipeline Analysis: a Strategic Model. Technical Report, Graduate School of Business, University of Cape Town.

Kaplinsky R. 2005. Globalisation, Poverty and Inequality: Between a Rock and a Hard Place. London: Polity Press.

Kriel A. 2006. Morris' job data not authoritative. Business Report, 10 October.

Lane C \& Bachmann R (editors). 1998. Trust within and between organisations: conceptual issues and empirical applications. Oxford: Oxford University Press.

Lawton-Smith H, Dickson K \& Lloyd-Smith S. 1991. There are two sides to every story: innovation and collaboration within networks of small and large firms. Research Policy, 20:457-468.

Leedy PD \& Ormrod JE. 2001. Practical research planning and design. $7^{\text {th }}$ Ed. New York/Ontario: Macmillan Publishing Company. 
Littler D, Leverick F \& Bruce M. 1995. Factors affecting the process of collaborative product development: A study of U.K. manufacturers of information and communications technology products. Journal of Product Innovation Management, 12:16-23.

Maree J. 1995. An industrial strategy for the textile sector. Cape Town: UCT Press.

Miles MB \& Huberman AM. 1994. Qualitative data analysis: a sourcebook of new methods. Newbury Park, CA: Sage Publications.

Morgan RM \& Hunt SD. 1994. The commitment-trust theory of relationship marketing. Journal of Marketing, 58(July):20-38.

Morris M. 2005. China's Dominance of Global Clothing and Textiles: Does Preferential trade Access Provide an Answer for Sub-Saharan Africa? IDS Bulletin.

Morris M \& Barnes J. 2006. Regional Development and Cluster Management: Lessons from South Africa [Online] Available from: http://www.saldru.uct.ac.za/prism_papers.html [Accessed: 2006-09-21].

Petersen KJ, Handfield RB \& Ragatz GL. 2003. A Model of Supplier Integration into New Product Development. Journal of Product Innovation Management, 20:284-299.

Rankine K. 2000. Baird law suit against M\&S will go to trial. Daily Telegraph [Online] Available from: http://www.telegraph.co.uk/money/main.jhtml?xml=/money/2000/06/30/cnms30.xml [Accessed: 200106-30]

Richardson GB. 1972. The Organisation of Industry. Economic Journal, 82:883-896.

Riek RF. 2001. From Experience: Capturing Hard-Won New Product Development Lessons in Checklists, 18:301-313 